\title{
LETTER
}

\section{The role for autopsy in the intensive care unit: technological considerations}

\author{
Carlos E Pompilio* \\ See related review by De Vlieger et al., http://ccforum.com/content/14/2/221
}

In their excellent review De Vlieger and colleagues [1] confirmed the steady decrease of nonforensic autopsies, a well-documented phenomenon in Europe, the United States [2], and Latin America, including Brazil (Figure 1). However, the causes usually attributed to explain this phenomenon, from my point of view, are not causes, but consequences of a change occurring with regard to the concept of disease. The concept of disease should be considered as what truly rules the art and science of medicine, giving direction to procedures as well as yielding pathways to research. Hofmann [3] argues that

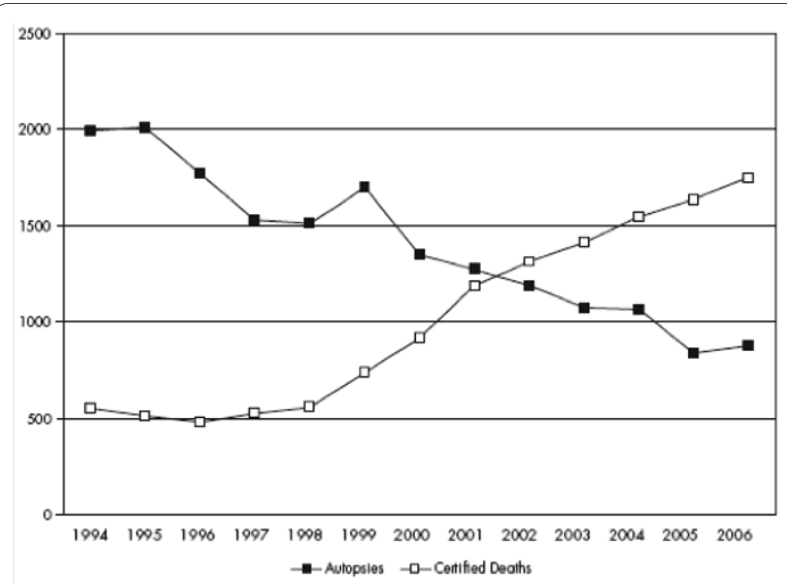

Figure 1. Rate of autopsied versus certified deaths at Hospital das Clinicas da Faculdade de Medicina da Universidade de Sao Paulo from 1994 to 2006. Modified from [5]. the contemporary concept of disease is technologically constituted. That means, 'technology provides the physiological, biochemical, and morphological entities that are applied in defining diseases'. I believe the decline of clinical autopsy is the result of a rearrangement of conceptual frameworks working on the contemporary medical rationality [4]. Trying 'to convince' intensive care doctors about the value of autopsies based only on their value per se will not work [5]. The autopsies must aggregate value to the procedure itself: new techniques and new insights, as pointed out by De Vlieger and colleagues. In fact, a new status in medical rationality is needed, otherwise the decline will continue.

\section{Competing interests}

The author declares that he has no competing interests.

Published: 5 July 2010

\section{References}

1. De Vlieger GYA, Mahieu EMJL, Meersseman W: Clinical review: What is the role for autopsy in the ICU? Crit Care 2010, 14:221.

2. Shojania KV, Burton EC: The vanishing nonforensic autopsy. N Engl J Med 2008, 358:873-875

3. Hofmann B: The technological invention of disease. Med Humanities 2001, 27:10-19.

4. Burton JL, Underwood J: Clinical, educational, and epidemiological value of autopsy. Lancet 2007, 369:1471-1480.

5. Pompilio CE, Vieira JE: The technological invention of disease and the decline of autopsies. Sao Paulo Med J 2008, 126:71-72.

doi:10.1186/cc9075

Cite this article as: Pompilio CE: The role for autopsy in the intensive care unit: technological considerations. Critical Care 2010, 14:426.
*Correspondence: carlos.pompilio@gmail.com

Surgical Intensive Care Unit - Gastroenterology Division, School of Medicine - Universidade de Sao Paulo, Av. Dr. Enéas de Carvalho Aguiar, 255 - 90 andar 05403-900 - São Paulo - SP - Brasil 